\title{
ANÁLISE DA ATUAÇÃO DO ESTADO NA FISCALIZAÇÃO DAS BARRAGENS DE MINERAÇÃO: O CASO SAMARCO ${ }^{1}$
}

ANALYSIS OF THE STATE'S PERFORMANCE IN THE SUPERVISION OF MINING DAMS: THE

SAMARCO'S CASE

Isabella Marques SILVA ${ }^{2}$

ISSUE DOI: 10.21207/2675-0104.2019.924

\begin{abstract}
RESUMO
O objetivo geral do presente trabalho é investigar em que consiste o dever de fiscalização do Estado quanto às barragens de mineração, tratando especificamente da barragem do Fundão, da mineradora Samarco. Este trabalho monográfico propõe-se a analisar a previsão legal a respeito do assunto e verificar se houve qualquer falha ou omissão por parte dos órgãos fiscalizadores. Faz-se uma análise sobre a origem da legislação ambiental e todo o seu desenvolvimento até os dias atuais, bem como um estudo profundo da legislação aplicável à segurança de barragens, para depois passar para a questão da barragem do Fundão e qual foi a real atuação dos órgãos responsáveis pela fiscalização dessas estruturas.
\end{abstract}

Palavras-chave: Barragem. Fiscalização. Mineração.

\section{ABSTRACT}

The general objective of the present work is to investigate what is the State's duty in the inspection of the mining dams, specifically dealing with Samarco's Fundão dam. This monographic work proposes to analyze the legal provision on the subject and to verify if there was any failure or omission by the supervisory bodies. An analysis is made of the origin of environmental legislation and all its development to date, as well as an in-depth study of the legislation applicable to dam safety, and then

\footnotetext{
${ }^{1} \mathrm{O}$ presente artigo sintetiza a monografia de conclusão da pesquisa, realizada para o Programa Interno de Bolsas de Iniciação Científica (PIBIC 2018-2019) da Faculdade de Direito de Franca (FDF), Franca/SP.

${ }^{2}$ Discente da Faculdade de Direito de Franca (FDF), Franca/SP. Bolsista do Programa Interno de Bolsas de Iniciação Científica (PIBIC 2018-2019).
} 
to the issue of the Fundão dam and what was the real action of the bodies responsible for overseeing these structures.

Keywords: Dam. Supervision. Mining.

1

\section{INTRODUÇÃO}

A presente pesquisa se insere no campo do Direito Ambiental e tem como escopo a análise da fiscalização das barragens de mineração no Brasil, tratando especificamente da atuação do Estado no caso da barragem do Fundão, da mineradora Samarco, que se rompeu em novembro de 2015 em Minas Gerais. Um desastre dessa proporção, considerado na época como o maior desastre socioambiental da história do país, levanta questões sobre eventuais falhas ou negligências por parte dos órgãos fiscalizadores. O objetivo da presente pesquisa é analisar de que maneira o Estado falhou nas atribuições de fiscalizar essas estruturas. Para isso, foi feito um estudo bibliográfico e documental, com consulta à legislação correspondente à matéria. Foi feito um estudo da Lei 12.334/10, que cria a Política Nacional de Segurança de Barragens e estabelece padrões de segurança para essas estruturas. São apresentados os órgãos responsáveis pela fiscalização das barragens de mineração, e passa-se a um estudo das funções desses órgãos e como se deu a fiscalização da barragem do Fundão. Por fim, foram apontadas algumas mudanças legislativas na fiscalização das barragens desde o desastre.

\section{A LEGISLAÇÃO ACERCA DAS BARRAGENS DE MINERAÇÃO NO BRASIL E O CASO SAMARCO}

As barragens de mineração são estruturas feitas com o objetivo de disposição temporária ou final dos rejeitos da atividade minerária. Elas surgiram na década de 1930 e os problemas relacionados a suas estruturas sempre foram frequentes. Rejeito é um material sem qualquer valor econômico, pois é aquilo que não é aproveitado ao final do processo de beneficiamento, que transforma o minério bruto em matéria-prima.

As barragens são estruturas construídas ao longo do tempo através de alteamentos sucessivos, que aumentam sua capacidade de armazenamento até chegar ao limite previsto em seu projeto inicial. $\mathrm{O}$ método utilizado na barragem do Fundão e em grande parte das barragens 
do Brasil, incluindo a de Brumadinho, que se rompeu em janeiro, é o método de alteamento a montante, em que o próprio rejeito solidificado é utilizado como base para a construção do próximo dique. Esse método de alteamento é o mais antigo, mais econômico, mais simples e perigoso. Os acidentes relacionados a essas estruturas são frequentes, e por isso esse método é proibido em alguns países, como Peru e Chile, que estão no limite de duas placas tectônicas, e um abalo sísmico pode comprometer as estruturas.

\subsection{A POLÍTICA NACIONAL DE SEGURANÇA DE BARRAGENS (LEI № 12.334/10)}

Em 21 de setembro de 2010 foi publicada a Lei $\mathrm{n}^{\circ} 12.334^{3}$, que criou a Política Nacional de Segurança de Barragens (PNSB), destinada às barragens de acumulação de água para quaisquer usos, à disposição final ou temporária de rejeitos e à acumulação de resíduos industriais. Essa política tem como objetivo garantir a observância de padrões de segurança para reduzir a possibilidade de acidentes e suas consequências.

Para efeitos da Lei, barragem é "qualquer estrutura em um curso permanente ou temporário de água para fins de contenção ou acumulação de substâncias líquidas ou de misturar de líquidos e sólidos, compreendendo o barramento e as estruturas associadas" .

Estão inseridas na PNSB quaisquer barragens que preencham ao menos uma das características previstas no artigo $1^{\circ}$, parágrafo único da Lei $12.334 / 10^{5}$, que dispõe sobre a altura do maciço, a capacidade total do reservatório, o tipo de resíduo desse reservatório e a categoria de dano potencial associado.

\footnotetext{
${ }^{3}$ BRASIL. Lei $\mathrm{n}^{\circ}$ 12.334, de 20 de set. de 2010. Estabelece a Política Nacional de Segurança de Barragens destinadas à acumulação de água para quaisquer usos, à disposição final ou temporária de rejeitos e à acumulação de resíduos industriais, cria o Sistema Nacional de Informações sobre Segurança de Barragens. Brasília, 20 de setembro de 2010. Disponível em: http://www.planalto.gov.br/ccivil_03/_Ato2007-2010/2010/Lei/L12334.htm. Acesso em: 12 ago. 2019.

${ }^{4}$ Idem, art. $2^{\circ}$, I.

5 a) Altura do maciço, contada do ponto mais baixo da fundação à crista, maior ou igual a $15 \mathrm{~m}$ (quinze metros);

b) Capacidade total do reservatório maior ou igual a 3.000.000 $\mathrm{m}^{3}$ (três milhões de metros cúbicos); c) Reservatório que contenha resíduos perigosos conforme normas técnicas aplicáveis; d) Categoria de dano potencial associado, médio ou alto, em termos econômicos, sociais, ambientais ou de perda de vidas humanas, conforme definido no art. $6^{\circ}$.
} 
A lei estabelece que é dever do empreendedor garantir a segurança de sua barragem. Empreendedor é a pessoa física ou jurídica que detém o direito real sobre as terras onde estão as barragens. Cabe a ele o desenvolvimento de ações para evitar quaisquer acidentes. São estabelecidas uma série de deveres que esse empreendedor deve cumprir, elencadas a seguir.

\subsection{PLANO DE SEGURANÇA DE BARRAGENS - PSB}

O Plano de Segurança de Barragens é um documento feito pelo empreendedor que serve para nortear toda a gestão de segurança da barragem. Para as barragens já existentes antes da promulgação da PNSB, foi estabelecido um prazo de dois anos para a implementação desse plano (até 20 de setembro de 2012), que deve ser aprovado pelo respectivo órgão fiscalizador. O Plano deve conter, no mínimo ${ }^{6}$ : informações gerais sobre a barragem e o empreendedor; documentação técnica do empreendimento; planos e procedimentos, registros e controles; relatórios de inspeção; revisão periódica de segurança da barragem; e plano de ação de emergência, quando exigido.

Segundo o artigo $8^{\circ}$ da Lei, a periodicidade de atualização, a qualificação do responsável técnico, o conteúdo mínimo e o nível de detalhamento do PSB deverão ser estabelecidos pelo respectivo órgão fiscalizador.

\subsection{REVISÃO PERIÓDICA DE SEGURANÇA DE BARRAGENS - RSB}

\footnotetext{
${ }^{6}$ Art. $8^{\circ}$ O Plano de Segurança da Barragem deve compreender, no mínimo, as seguintes informações: I - identificação do empreendedor; II - dados técnicos referentes à implantação do empreendimento, inclusive, no caso de empreendimentos construídos após a promulgação desta Lei, do projeto como construído, bem como aqueles necessários para a operação e manutenção da barragem; III - estrutura organizacional e qualificação técnica dos profissionais da equipe de segurança da barragem; IV manuais de procedimentos dos roteiros de inspeções de segurança e de monitoramento e relatórios de segurança da barragem; V - regra operacional dos dispositivos de descarga da barragem; VI - indicação da área do entorno das instalações e seus respectivos acessos, a serem resguardados de quaisquer usos ou ocupações permanentes, exceto aqueles indispensáveis à manutenção e à operação da barragem; VII - Plano de Ação de Emergência (PAE), quando exigido; VIII - relatórios das inspeções de segurança; IX - revisões periódicas de segurança.
} 
A Revisão Periódica de Segurança de Barragem faz parte do PSB e serve para reexaminar os aspectos de segurança da barragem. Deve também indicar possíveis melhorias e correções para reduzir os riscos associados às estruturas. Ao ser concluída a RPSB, deve ser emitida uma Declaração de Condição de Estabilidade, que será anexada ao PSB e inserida no SIGBM.

\subsection{INSPEÇÕES REGULARES DE SEGURANÇA DE BARRAGENS - IRSB}

Os empreendedores devem também realizar inspeções regulares de segurança, com seus respectivos relatórios de inspeção regular, com periodicidade definida pelo órgão fiscalizador. Para as barragens de mineração, atualmente a frequência é semestral.

As inspeções regulares das barragens de mineração compõem-se de: ficha de inspeção regular; relatório de inspeção regular; extrato de inspeção regular e; declaração de condição de estabilidade.

O empreendedor deve também enviar uma Declaração de Condição de Estabilidade, que é um documento que atesta a condição de estabilidade da estrutura em análise, semestralmente, entre os dias $1^{\circ}$ e 31 de março e $1^{\circ}$ e 30 de setembro. Essa declaração deverá ser assinada tanto pelo responsável técnico por sua elaboração quanto pelo empreendedor da barragem. Também é necessário o envio desse documento quando da realização de uma Revisão Periódica de Segurança de Barragem. O não envio da DCE implica na interdição imediata da estrutura.

\subsection{PLANO DE AÇÕES EMERGENCIAIS (PAE)}

O Plano de Ações Emergenciais integra o Plano de Segurança da Barragem e é exigido para as barragens com dano potencial associado alto. Nele são identificadas as situações de emergência que podem colocar a barragem em risco. Deve conter as orientações necessárias para que os danos sejam minimizados num momento de sinistro, como, por exemplo, a forma de alerta para a população. Também deve identificar os agentes que serão notificados caso algum acidente aconteça. 
O Plano deve conter, no mínimo: a identificação e análise das possíveis situações de emergência; procedimentos para identificação e notificação de mau funcionamento ou de condições potenciais de ruptura da barragem; procedimentos preventivos e corretivos a serem adotados em situações de emergência, com indicação do responsável pela ação; e estratégia e meio de divulgação e alerta para as comunidades potencialmente afetadas em situação de emergência ${ }^{7}$.

A Lei também prevê que o PAE deve estar disponível no empreendimento e nas prefeituras envolvidas, e deve também ser encaminhado às autoridades competentes e aos organismos de defesa civil (parágrafo único).

\section{6 ÓRGÃOS RESPONSÁVEIS PELA FISCALIZAÇÃO DAS BARRAGENS DE MINERAÇÃO}

Os órgãos envolvidos na fiscalização das barragens para fins de contenção de rejeitos de mineração são a Agência Nacional de Águas (ANA), a Agência Nacional de Mineração (ANM) e o Conselho Nacional de Recursos Hídricos (CNRH).

A ANA fiscaliza a segurança de barragens de acumulação de água localizadas em rios de domínio da União para as quais emitiu outorga, com exceção daquelas utilizadas para a geração de energia elétrica. A este órgão cabe também as atribuições de organizar, implantar e gerir o Sistema Nacional de Informações sobre Segurança de Barragens (SNISB); promover a articulação entre órgãos fiscalizadores de barragens; e coordenar a elaboração do Relatório de Segurança de Barragens e encaminhá-lo, anualmente, ao Conselho Nacional de Recursos Hídricos, que por sua vez o encaminha ao Congresso Nacional até o dia 20 de setembro de cada ano.

O Relatório de Segurança de Barragens (RSB) é um documento importante cujo objetivo é disponibilizar para toda a sociedade as informações relacionadas à segurança das barragens brasileiras. Nele estão

\footnotetext{
${ }^{7}$ BRASIL. Lei ${ }^{\circ}$ 12.334, de 20 de set. de 2010, art. 12. Estabelece a Política Nacional de Segurança de Barragens destinadas à acumulação de água para quaisquer usos, à disposição final ou temporária de rejeitos e à acumulação de resíduos industriais, cria o Sistema Nacional de Informações sobre Segurança de Barragens. Brasília, 20 de setembro de 2010. Disponível em: http://www.planalto.gov.br/ccivil 03/ Ato2007-2010/2010/Lei/L12334.htm. Acesso em: 13 ago. 2019.
} 
inseridas todas as informações relevantes e serve como um registro da evolução da segurança de barragens no país.

A Agência Nacional de Mineração (ANM) é uma autarquia federal vinculada ao Ministério de Minas e Energia (MME) responsável pela fiscalização das barragens de mineração, sendo ela responsável pela outorga de direitos minerários para fins de disposição final ou temporária de rejeitos. Ela foi criada para substituir o Departamento Nacional de Produção Mineral (DNPM) que tinha esses deveres antes de ser extinto, em 2017.

Ao Conselho Nacional de Recursos Hídricos coube a função de estabelecer os critérios para a classificação das barragens quanto ao risco crítico, dano potencial associado e quanto ao volume. Este é um instrumento importante dessa Lei. Os critérios para essa classificação estão contidos na Resolução CNRH nº 143, de 10 de julho de 2012.

$\mathrm{O}$ risco crítico diz respeito às características da estrutura da barragem, como seu estado de conservação e atendimento ao Plano de Segurança da Barragem. O dano potencial associado (DPA), diz respeito às possíveis perdas humanas e prejuízos econômicos, sociais e ambientais que uma eventual ruptura pode acarretar. Tanto o risco crítico quanto o DPA podem ser classificados como baixo, médio ou alto. Para cada item é estabelecida uma pontuação para a barragem, e quanto maior essa pontuação, pior é o estado dela. Assim estabelece-se a matriz de risco crítico e dano potencial associado, e as barragens são classificadas de A a E. As informações necessárias para essa classificação são inseridas quando do cadastro da barragem no Sistema Integrado de Gestão de Segurança de Barragens de Mineração (SIGBM). Cabe a Agência Nacional de Mineração efetuar a classificação, baseada nas informações enviadas pelos empreendedores e também pelas informações colhidas em fiscalizações in loco.

Os prazos e procedimentos são discricionários para os órgãos fiscalizadores, mas sempre respeitando os prazos estipulados na Lei.

\subsection{SISTEMA NACIONAL DE INFORMAÇÕES SOBRE SEGURANÇA DE BARRAGENS (SNISB)}

A Lei 12.334/10 criou o Sistema Nacional de Informações sobre Segurança de Barragens (SNISB) para registrar as condições de segurança de barragens em todo o território nacional. Os órgãos 
fiscalizadores e os empreendedores devem enviar informações sobre as barragens de sua jurisdição, e cabe a Agência Nacional de Águas transformá-las num documento chamado Relatório Anual de Barragens.

Os responsáveis diretos pelo SNISB, de acordo com o artigo $17^{8}$, são: a Agência Nacional de Águas (ANA); os órgãos fiscalizadores; e os empreendedores.

\section{A FISCALIZAÇÃO DAS BARRAGENS DE MINERAÇÃO À ÉPOCA DO DESASTRE DA BARRAGEM DO FUNDÃO}

À época dos fatos, o órgão responsável pela fiscalização das barragens de mineração era o Departamento Nacional de Produção Mineral (DNPM), autarquia responsável pela outorga de direitos minerários, posteriormente substituído pela Agência Nacional de Mineração (ANM). A mudança foi feita com a justificativa de modernizar o setor mineral para atrair novos investimentos, tornar a indústria mais competitiva, inovadora e sustentável.

A Barragem do Fundão estava inserida na Política Nacional de Segurança de Barragens, e seu cadastro fora feito via Sistema de Relatório Anual de Lavra (RAL), posteriormente substituído pelo Sistema Integrado de Gestão de Segurança de Barragens de Mineração (SIGBM). De acordo com as informações declaradas no sistema RAL, a barragem foi classificada como de baixo risco crítico e alto dano potencial associado, o que significa que a estrutura estava estável, porém caso acontecesse alguma ruptura, os desastres seriam grandes. Ela estava enquadrada na categoria $\mathrm{C}$ da matriz de Risco crítico X DPA, que vai de A a E, sendo A a classificação de maior risco, e E, de menor risco.

Como visto anteriormente, o empreendedor tem a obrigação legal de garantir a segurança das barragens sob sua jurisdição, e cabe aos órgãos fiscalizadores verificar se essas obrigações estão sendo cumpridas. Segundo o artigo 16 da Lei 12.334/10, cumpre aos órgãos fiscalizadores: a) implementar e manter cadastro das barragens sob sua jurisdição; b)

\footnotetext{
${ }^{8}$ BRASIL. Lei ${ }^{\circ}{ }^{12.334}$, de 20 de set. de 2010, art. 17. Estabelece a Política Nacional de Segurança de Barragens destinadas à acumulação de água para quaisquer usos, à disposição final ou temporária de rejeitos e à acumulação de resíduos industriais, cria o Sistema Nacional de Informações sobre Segurança de Barragens. Brasília, 20 de setembro de 2010. Disponível em: http://www.planalto.gov.br/ccivil 03/ Ato2007-2010/2010/Lei/L12334.htm. Acesso em: 13 ago. 2019.
} 
exigir do empreendedor a anotação de responsabilidade técnica (ART), por profissional habilitado pelo Sistema Federal de Engenharia, Arquitetura e Agronomia (Confea) / Conselho Regional de Engenharia, Arquitetura e Agronomia (Crea), dos estudos, planos, projetos, construção, fiscalização e demais relatórios exigidos pela legislação; c) exigir do empreendedor o cumprimento das recomendações contidas nos relatórios de inspeção e revisão periódica de segurança; e d) exigir do empreendedor o cadastramento e a atualização das informações relativas à barragem.

O DNPM não possuía uma unidade com a atribuição específica de fiscalizar barragens de rejeitos, então tal atividade estava incluída no rol geral de fiscalização da atividade minerária.

O DNPM possuía o órgão central, que era a Diretoria de Fiscalização da Atividade Minerária (Difis), e os órgãos descentralizados, as superintendências regionais, subordinadas ao Diretor-Geral. Cabia às superintendências a realização de vistorias nas barragens, as chamadas fiscalizações in loco, em que os funcionários se deslocavam até a barragem para verificar se as informações declaradas pelo empreendedor correspondiam ao estado real da estrutura.

A PNSB facultou ao DNPM regulamentar critérios para a classificação quanto ao risco crítico e DPA, além daqueles estabelecidos pelo Conselho Nacional de Recursos Hídricos, para complementá-los, porém isso não foi feito. As sanções previstas para o caso de descumprimento das exigências da PNSB por parte dos empreendedores eram a emissão de autos de infração, aplicação de multas e emissão de autos de interdição.

Os instrumentos que a autarquia possuía para fiscalizar as barragens eram: as informações inseridas no sistema de Relatório Anual de Lavra; o Plano de Segurança da Barragem, o Plano de Ação de Emergência, a Declaração de Condição de Estabilidade, os extratos das inspeções regulares e especiais - essas caso houvesse alguma anomalia que resultasse na pontuação máxima de 10 pontos quanto ao risco crítico - e as fiscalizações in loco.

O profissional responsável por declarar todas essas informações precisa ter anotação de responsabilidade técnica (ART) e registro no Conselho Regional de Engenharia, Arquitetura e Agronomia (CREA).

A fiscalização era realizada tanto à distância, pela análise dos documentos enviados pelos empreendedores, quanto pessoalmente, durante as vistorias. Passemos a análise de cada uma delas. 


\subsection{ANÁLISE PROCESSUAL}

As orientações para a análise processual constavam no Manual de Fiscalização de Barragens de Mineração.

Foi apurado pelo Tribunal de Contas da União, em auditoria operacional realizada no DNPM em 2016 que o cadastro de barragens se limitava ao fornecimento meramente declaratório de dados pelos empreendedores, pois não havia uma forma concreta de análise rotineira das informações declaradas.

\footnotetext{
O DNPM não dispõe de meios e instrumentos concretos, como o uso de softwares de georreferenciamento, serviços de imagens por satélite ou tecnologias como veículos aéreos não tripulados (Vants), além de cruzamento de dados ou vínculos de cooperação com órgãos ambientais ou universidades, para auxiliar na verificação e conferência sistemática e rotineira da veracidade dos dados informados no cadastro pelos empreendedores ${ }^{9}$
}

O Sistema RAL não possuía uma forma de emissão de alertas ou qualquer tipo de notificação que avisasse o órgão fiscalizador sobre qualquer alteração realizada pelo empreendedor, para facilitar a comparação das informações do cadastro com as dos anos anteriores. Uma eventual reclassificação teria que ser feita manualmente, pois alterações não eram detectadas automaticamente pelo sistema. A verificação das informações do cadastro não era confiável, e o empreendedor poderia facilmente omitir alguma informação para tentar minimizar os riscos e conseguir uma classificação de risco menos grave em sua barragem.

Segundo a Portaria DNPM 416/2012, o envio da Declaração de Condição de Estabilidade devia ser enviado por meio do sítio eletrônico do DNPM. Todavia, o site não tinha capacidade para carregar os arquivos. Portanto, utilizava-se o e-mail da autarquia, e o meio físico.

$\mathrm{Na}$ prática, o que foi constatado é que os documentos enviados eram inseridos diretamente nos processos minerários dos empreendedores, que eram físicos, e geralmente eram verificados somente quando estava chegando o dia da vistoria (fiscalização in loco) daquele empreendimento.

De forma geral, o DNPM não conseguia verificar à distância a veracidade das informações declaradas pelos empreendedores, então a

9 BRASIL, Tribunal de Contas da União. TC 032.034/2015-6, 2016. Disponível em: https://portal.tcu.gov.br/lumis/portal/file/fileDownload.jsp?fileId=8A8182A25753C20F0157587B1F 4C0870\&inline $=1$. Acesso em: 10 abr. 2019. 
fiscalização "de escritório" funcionava tão-somente como um controle de checklist, e não era feita uma análise crítica sobre a matéria informada. Além disso, o órgão não tinha controle efetivo do envio dos documentos por parte dos empreendedores, ainda que para verificar o estrito cumprimento da obrigação prevista em Lei.

Não existia um sistema eletrônico único para armazenar as informações relevantes sobre as barragens para fins de fiscalização. A tecnologia da informação era muito precária. Também não havia qualquer tipo de tecnologia que emitisse notificações sobre a inadimplência do empreendedor.

Quanto a Declaração de Condição de Estabilidade, o DNPM não analisava as recomendações que eventualmente eram feitas pelo engenheiro responsável. O órgão consultava somente se a estabilidade havia sido atestada, e mesmo essa consulta de checklist não era tempestiva.

\subsection{FISCALIZAÇÃO IN LOCO}

As vistorias são uma parte de extrema importância do processo de fiscalização, pois é o momento em que os técnicos se deslocam até as barragens para verificar a condição dessas estruturas. São chamadas de fiscalizações in loco.

O planejamento das vistorias do DNPM era feito pela Diretoria de Fiscalização (Difis), e as especificações eram responsabilidade de cada superintendência. As metas eram quantitativas, referiam-se à quantidade de fiscalizações realizadas no período de um ano.

A prioridade da Difis era a vistoria de barragens com risco crítico alto, e os planos de fiscalização não dispunham explicitamente sobre outros aspectos utilizados para a escolha das barragens que seriam fiscalizadas. Isso se deve ao fato de o DNPM não possuir um procedimento de análise rotineira e eficaz dos documentos recebidos, os quais têm informações relevantes sobre as estruturas.

Apesar da prioridade conferida às barragens de risco crítico alto pela Difis, na prática esse critério não era seguido totalmente pelas superintendências, que praticamente não tinham qualquer rotina de planejamento de fiscalizações.

A despeito das alegações da Difis quanto às diretrizes a serem seguidas pelas superintendências, os números levantados por esta equipe indicam situação diversa. Das fiscalizações in loco 
executadas no período de 2012 a 2015 , apenas $6 \%$ foram feitas em barragens classificadas como de alto risco crítico, enquanto 93\% compreenderam as de baixo risco. Não obstante a maioria das barragens de rejeitos no País ser classificada como de risco baixo, do total das estruturas de alto risco inseridas na PNSB (28), apenas $35 \%$ sofreram fiscalização do DNPM no período considerado. ${ }^{10}$

Foi analisado que não havia interatividade entre a Difis e as unidades descentralizadas. A diretoria e as superintendências não discutiam planos de fiscalização. Além disso, as diretrizes estabelecidas no processo de fiscalização não levavam em conta as informações colhidas pelas superintendências durante todo o processo de fiscalização, então nem sempre elas representavam as necessidades reais das superintendências.

O acompanhamento das vistorias era feito por meio de relatórios mensais enviados pelas superintendências à Difis, sem qualquer obrigação imposta às superintendências para que detalhasse para a Difis as especificações das vistorias.

Das barragens classificadas com alto dano potencial associado, no período de 2012 a 2015, de 185 estruturas dessa categoria no país, 52\% foram fiscalizadas.

Considerando a matriz de risco crítico e DPA, apenas $28 \%$ das barragens classificadas como de categoria A, ou seja, de alto risco e alto dano potencial associado, foram fiscalizadas no mesmo período.

$\mathrm{O}$ estado de Minas Gerais possui o maior número de barragens inseridas na PNSB, são 220 estruturas cadastradas. Dessas barragens, 144 não foram vistoriadas uma única vez no período de 2012 a 2015.

Nos estados de Minas Gerais, Mato Grosso, São Paulo e Tocantins, no período de 2012 a 2015 menos de 40\% das barragens inseridas na Lei 12.334/10 foram vistoriadas.

Em 2015 foram realizadas 48 vistorias na superintendência de Minas Gerais; 34 delas foram feitas em barragens da empresa Samarco Mineração S.A, e tais vistorias foram realizadas somente após o desastre com a Barragem do Fundão, no fim do ano.

$\mathrm{O}$ acidente com essa barragem motivou uma força-tarefa para fiscalizar todas as barragens de Minas Gerais, então após o desastre 100\% das barragens inseridas na PNSB naquele estado foram fiscalizadas.

10 BRASIL. Tribunal de Contas da União. TC 032.034/2015-6, 2016. Disponível em: https://portal.tcu.gov.br/lumis/portal/file/fileDownload.jsp?fileId=8A8182A25753C20F0157587B1F 4C0870\&inline $=1$. Acesso em: 11 abr. 2019. 
Durante as vistorias, os técnicos deviam verificar se os dados constantes do cadastro no sistema RAL correspondiam à realidade da barragem, e se havia alguma barragem não cadastrada.

Deviam também verificar os documentos obrigatórios previstos na Política Nacional de Segurança de Barragens, como o Plano de Segurança da Barragem e cópias das declarações de condição de estabilidade.

Além disso, as orientações do Manual de Fiscalização eram genéricas e não tinham qualquer ficha ou modelo para ser preenchido com o objetivo de padronizar as análises.

O assessoramento técnico do DNPM contratou uma empresa para aperfeiçoar as fiscalizações in loco, pois os próprios técnicos do DNPM não tinham o conhecimento técnico necessário para a realização de vistorias completas, detalhadas e patronizadas.

\subsection{DEFICIÊNCIA ORÇAMENTÁRIA E CARÊNCIA DE RECURSOS HUMANOS}

O DNPM carecia de recursos para funcionar. Não existia um orçamento específico para a fiscalização de barragens, então o orçamento destinado às fiscalizações englobava também todas as demais.

A partir de 2010 o total autorizado para despesas discricionárias da autarquia, incluídas as atividades de fiscalização, sofreram uma diminuição progressiva.

As superintendências estavam sofrendo uma séria crise financeira, e algumas estavam em iminência de fechamento.

Os percentuais de orçamento executado no órgão fiscalizador durante os anos de 2013, 2014 e 2015 foram de 118\%, 95\% e 94\%, respectivamente. Contabilizando o orçamento necessário para um bom funcionamento da atividade de fiscalização minerária, o valor seria $100 \%$ superior ao consignado no ano de 2015:

Desse modo, entre fiscalizações presenciais e de análise de documentos técnicos e considerando, ainda, as metas institucionais, o quantitativo de recursos humanos e a produtividade de cinco fiscalizações presenciais e cinco análises de documentos por mês, por técnico, em ano de dez meses, o estudo apontou capacidade de onze mil fiscalizações ao ano, a um custo total estimado de $\mathrm{R} \$$ 6.054.000,00. Contabilizando, ainda, as necessidades de capacitação dos agentes fiscalizadores, chegou-se ao montante de 
R \$ 8.084.336,00 para toda a Ação Fiscalização das Atividades Minerárias, ou seja, valor $100 \%$ superior ao efetivamente consignado no orçamento referente àquele ano. ${ }^{11}$

Além disso, o DNPM tinha uma grande deficiência em seu quadro técnico, frente a grande demanda de trabalho da autarquia.

Em 27 de dezembro de 2004, a Lei 11.046 foi promulgada, estabelecendo a criação do plano de carreira (PCC) e o plano especial de cargos (PEC) do DNPM. Foram criados 1.200 cargos, sendo seiscentos de especialistas em recursos minerais, 200 de analista administrativo, 200 de técnico em atividades de mineração e duzentos de técnico-administrativo.

Somadas a essas, também havia os cargos vagos, somando o total de 1.603 vagas criadas.

Foram realizados dois concursos desde o advento dessa lei, um em 2005 e um em 2009. Desde então, nenhum outro foi realizado. Das 1.200 vagas criadas, 450 estavam ocupadas em 2016. O Ministério do Planejamento, Orçamento e Gestão (MP) não liberou os candidatos aprovados para nomeação, então as vagas remanescentes não foram preenchidas. Em 2016, a autarquia contava com aproximadamente $62 \%$ da quantidade de funcionários necessária para a realização de todas as atividades. Nesse mesmo período, cerca de $36 \%$ dos servidores da autarquia estavam aptos a se aposentar.

Em 1989 o DNPM tinha um quadro de 1.430 servidores, e em 2005 apenas 811, o que é incompatível com o crescimento da demanda no setor minerário e o aumento das atribuições da autarquia. Em 2016 o número era de 1.171 servidores, porém o aumento não foi suficiente para superar o esvaziamento que ocorreu no período até 2005.

Ademais, o departamento enfrentava dificuldades para implementar planos de capacitação sistemáticos para qualificar os servidores responsáveis pela fiscalização das barragens, devido a insuficiência de recursos humanos, a limitação orçamentária e a falta de unidade específica para a fiscalização de barragens de mineração, pois os funcionários tinham que exercer também outras funções.

Em suma, a deficiência no quadro de servidores e a limitação orçamentária impediam o cumprimento das inúmeras funções atribuídas ao Departamento, o que se tornou ainda mais grave após o advento da lei 12.334/10 que criou a PNSB e aumentou o número de funções da autarquia.

\section{O ACIDENTE NA BARRAGEM DO FUNDÃO DA MINERADORA SAMARCO}

11 BRASIL, Tribunal de Contas da União. TC 032.034/2015-6, 2016, p. 44. Disponível em: https://portal.tcu.gov.br/lumis/portal/file/fileDownload.jsp?fileId=8A8182A25753C20F0157587B1F 4C0870\&inline $=1$. Acesso em: 17 maio 2019. 
A Barragem do Fundão fazia parte, junto com outras estruturas, do complexo minerário do Germano, e era utilizada para a disposição de rejeitos de mineração.

Essa barragem estava inserida na Política Nacional de Segurança de Barragens, e de acordo com as informações declaradas pela Samarco, sua classificação era de baixo risco crítico e alto dano potencial associado, o que a enquadrava na categoria $\mathrm{C}$ da matriz de risco crítico e DPA.

A última vistoria realizada pelo DNPM foi em 2012, e naquela época a barragem ainda não tinha um Plano de Segurança, pois, de acordo com a Lei 12.334/10, foi definido um prazo de dois anos, para as barragens que já existiam à época da promulgação da lei, para que os relatórios de implantação do PSB fossem encaminhados às Superintendências, detalhando suas ações e seu cronograma. O prazo se esgotaria no dia 20/09/2012, porém foi estabelecida uma data limite de 20/09/2014 para a implantação definitiva do documento.

O cronograma de implantação do PSB foi protocolizado no dia 08/10/2012, na Superintendência de Minas Gerais. O documento foi analisado e julgado satisfatório pelo DNPM. Como o prazo se esgotou em 20/09/2012, a empresa foi autuada por entregá-lo intempestivamente. Todavia, o auto de infração foi emitido apenas em abril de 2014.

A estrutura estava regularmente declarada no sistema RAL desde 2012, e as inspeções regulares estavam sendo registradas na periodicidade estabelecida pelo órgão fiscalizador.

Quanto a declaração de condição de estabilidade, a primeira não foi enviada dentro do prazo (31/03/2013), e a empresa foi autuada em 27 de novembro de 2014. As declarações correspondentes aos anos de $2014 \mathrm{e}$ 2015 foram entregues dentro do prazo.

As declarações estavam de acordo com o que a Portaria DNPM 416/2012 determinava, e todas declaravam expressamente a estabilidade da estrutura. A última declaração de condição de estabilidade havia sido protocolizada em setembro de 2015 , cerca de dois meses antes do desastre. Essa declaração, na época, tinha a validade de um ano, então ela deveria garantir que a estrutura estaria estável durante esse período.

A empresa teria até a data de 20/09/2019 para executar a revisão periódica de segurança, prazo estabelecido de acordo com sua classificação $\mathrm{C}$ na matriz de risco crítico e DPA. Também haveria a necessidade de revisão caso a empresa tivesse feito alteamentos ou modificações nos rejeitos depositados, se essas alterações não estivessem previstas no projeto inicial e na última licença ambiental. 
No mesmo dia, os representantes da Samarco notificaram, às 21h22min, a Superintendência de Minas Gerais, via correio eletrônico. No dia seguinte, técnicos dessa Superintendência inspecionaram a área e lavraram auto de interdição, interditando e paralisando imediatamente as atividades de todo o empreendimento.

Após o desastre o DNPM analisou o Plano de Segurança da Barragem do Fundão e seu respectivo Plano de Ação de Emergência, e foram observadas algumas incongruências.

Segundo o artigo $6^{\circ}$, parágrafo $2^{\circ}$, da Portaria $\mathrm{n}^{\circ} 526$ do DNPM, revogada pela Portaria $\mathrm{n}^{\circ} 70.389$, o PSB deve estar no local mais próximo da barragem:

\begin{abstract}
$\S 2^{\circ} \mathrm{O}$ documento físico do PAEBM deverá estar inserido no Plano de Segurança da Barragem de Mineração assim como deve estar, também, em local de fácil acesso no próprio local da barragem e, na inexistência de escritório local, na planta de beneficiamento, no escritório da mina, na regional ou sede do empreendedor, o que for mais próximo da barragem. ${ }^{12}$
\end{abstract}

Foi verificado que no caso da Barragem do Fundão essa norma não foi cumprida. Também foi constatada a ausência de cronogramas de testes de equipamentos hidráulicos, elétricos e mecânicos, o que deveria constar nos volumes II e III do Plano de Segurança.

Quanto ao Plano de Ação de Emergência, este também não estava no local mais próximo da barragem. Além disso, apesar de conter os procedimentos de notificação à população, não constava no documento a forma de comunicação com a equipe de salvamento, nem mesmo com a Zona de Autossalvamento, que corresponde à região onde a responsabilidade de avisos e alerta à população incumbem ao empreendedor, pois não há tempo suficiente para uma intervenção de autoridades responsáveis por situações de emergência.

O Plano de Ação de Emergência devia conter um estudo e mapa de cenários, que dariam a previsão das áreas atingidas numa eventual ruptura. Ocorre que o DNPM verificou que as áreas inundadas pelo rompimento da barragem não correspondiam ao que constava nesse documento.

\footnotetext{
${ }^{12}$ BRASIL. Departamento Nacional de Produção Mineral. Portaria n ${ }^{\circ}$ 526, de 09 de dez. de 2013. Art. $6^{\circ}, \S 2^{\circ}$. Brasília, 09 de dezembro de 2013. Disponível em: http://www.anm.gov.br/acesso-ainformacao/legislacao/portarias-do-diretor-geral-do-dnpm/portarias-do-diretor-geral/portaria-no-526em-09-12-2013-do-diretor-geral-do-dnpm/view. Acesso em: 21 maio 2019.
} 
A Portaria também elencava quais autoridades deveriam receber uma cópia do Plano (Prefeituras e Defesas Civis municipais e estaduais afetadas, além de cópia digital para o CENAD), porém essa relação, bem como os protocolos de recebimento, não constava dos anexos do PAE.

Não havia no documento registros de treinamentos e simulações com as prefeituras e demais instituições indicadas pelo governo municipal, conforme determinava o artigo 11, II da Portaria, tampouco registros de treinamentos internos envolvendo a equipe de segurança da barragem, conforme previa o inciso III do mesmo artigo.

Foi constatado que não constava no Plano os sistemas de alerta e avisos, de forma rápida e eficaz, para a população da zona de autossalvamento.

Observa-se que a empresa, de modo geral, cumpriu a obrigação legal de enviar todos os documentos necessários para a fiscalização da barragem. Ocorre que tais documentos não correspondiam à realidade do empreendimento. O dever legal de garantir a estabilidade da barragem é, por lei, do empreendedor. Isso significa que ele é o responsável legal pela declaração das informações constantes do cadastro do empreendimento, pela realização de inspeções regulares, pela declaração de condição de estabilidade e diversos outros documentos já analisados. Na época do desastre com a barragem do Fundão, a análise quanto a veracidade das informações declaradas só era feita quando da fiscalização in loco, isso se essas ocorressem. Como foi visto, de acordo com as informações declaradas pela Samarco, a estrutura da barragem do Fundão estava estável, sua classificação era de baixo risco e não era necessário proceder a uma revisão de segurança ou inspeção especial, pois não havia riscos.

Por sua vez, o órgão fiscalizador não tinha recursos para verificar se essas informações correspondiam à realidade, devido à grave carência de recursos humanos, especialmente na Superintendência de Minas Gerais, unidade com o maior déficit de servidores e maior número de barragens inseridas na PNSB. Além disso, a autarquia enfrentava uma séria dificuldade orçamentária. Tais fatores impediam que o DNPM cumprisse suas inúmeras atribuições, e prejudicava de maneira imensurável a fiscalização das barragens. Dessa forma, os objetivos previstos na Lei $12.334 / 10$ não eram cumpridos. 


\section{5}

\section{AVANÇOS RECENTES NA LEGISLAÇÃO}

Após os dois grandes desastres recentes envolvendo barragens de mineração no Brasil, algumas mudanças legislativas ocorreram no que tange à fiscalização dessas estruturas.

A ANM ainda conta com um sério problema orçamentário e déficit de servidores, e, como não tem condições de arcar com todos os custos de um monitoramento eficaz das barragens de mineração, aumentou as atribuições dos empreendedores na fiscalização das estruturas. Entre as novas atribuições, estão:

Ficam proibidos em todo o território nacional os métodos de alteamento a montante ou desconhecido, de acordo com a Resolução $n^{\circ} 4$, de 15 de fevereiro de 2019 da Agência Nacional de Mineração (ANM) ${ }^{13}$. Atualmente existem cerca de 84 barragens no Brasil que utilizam estes métodos, e foram estabelecidos alguns prazos para que todas sejam descomissionadas ou descaracterizadas. Até dia 15 de agosto de 2019 os empreendedores deverão concluir um projeto técnico de descomissionamento $^{14}$ ou descaracterização ${ }^{15}$ dessas estruturas. Até fevereiro de 2020 deverão construir obras de reforço da barragem à jusante ou construção de nova estrutura de contenção à jusante; e até dia 15 de agosto de 2021 todos os empreendedores de barragens construídas ou alteadas pelo método a montante ou por algum método declarado como desconhecido devem concluir o descomissionamento ou descaracterização da barragem. Ficou vedada a realização de novos alteamentos desse tipo. As barragens com o método de alteamento a montante que estavam em operação até a data de entrada de vigor da Resolução poderão continuar funcionando até o dia 15 de agosto de 2021, e o prazo final para essas estruturas é dia 15 de agosto de 2023.

A sanção para quem não cumprir os prazos estabelecidos é a interdição dos empreendimentos.

Também ficou determinado que todos os empreendedores com barragens de mineração, independentemente do método, deverão, até dia 15 de agosto de 2019, implementar soluções para a redução da quantidade

\footnotetext{
${ }^{13}$ BRASIL. Diário oficial da União. Resolução no 4, de 15 de fevereiro de 2019. Agência Nacional de Mineração/Ministério de Minas e Energia. Brasília, 15 de fevereiro de 2019. Disponível em: http://www.in.gov.br/materia/-/asset_publisher/Kujrw0TZC2Mb/content/id/63799094/do1-2019-0218-resolucao-n-4-de-15-de-fevereiro-de-2019-63799056. Acesso em: 13 ago. 2019.

${ }^{14}$ Descomissionar uma barragem é fazer com que ela deixe de ser uma barragem. As opções são esvaziá-las ou integrá-las ao meio ambiente.

${ }^{15}$ Descaracterizar significa fazer com que a barragem exerça outra função, por exemplo, empilhamento do rejeito drenado.
} 
de água nas barragens, e devem ser imediatamente executadas após essa data.

Ficam proibidas instalações que incluam a presença humana na Zona de Autossalvamento - ZAS.

Todas as estruturas com dano potencial alto (DPA) deverão ser monitoradas em tempo integral, e cabe ao empreendedor a definição da tecnologia, dos instrumentos e dos processos de monitoramento visando sua interligação com o Sistema Integrado de Gestão de Segurança de Barragens de Mineração.

Ainda, o empreendedor desde 2017 é obrigado a elaborar um mapa de inundação, com a previsão das áreas potencialmente atingidas por um rompimento, para que sirva como critério na avaliação do dano potencial associado.

A Agência Nacional de Mineração ainda não abriu edital para concurso público, e a previsão é de que sejam abertas cerca de 600 vagas. A demanda é muito grande, e apenas alguns avanços legislativos não serão suficientes para a garantia da segurança se não houver investimento no setor para que a agência possa funcionar.

\section{CONSIDERAÇÕES FINAIS}

Os acidentes com barragens sempre foram frequentes, porém o diploma legal que trata especificamente do assunto só foi promulgado em 2010, com o advento da Lei 12.334/10 que cria a Política Nacional de Segurança de Barragens, com vistas a determinar os padrões de segurança para que os acidentes relacionados a essas estruturas sejam evitados. Essa Lei atribuiu ao Departamento Nacional de Produção Mineral, substituído pela Agência Nacional de Mineração (ANM), o dever de fiscalizar as barragens de mineração, e determinou que incumbe ao empreendedor o dever legal de garantir a segurança dessas estruturas. O empreendedor tem uma série de obrigações legais para com o órgão fiscalizador e a população, e grande parte da fiscalização é feita por ele próprio. Ao órgão fiscalizador cabe verificar se as informações declaradas pelo empreendedor correspondem à realidade da barragem, o que na prática, na época da barragem do Fundão, era feito de maneira precária. O DNPM passava por sérias dificuldades em seu quadro técnico e financeiro, então todas as suas funções, incluindo a fiscalização, ficavam prejudicadas. No caso da barragem do Fundão, a Samarco enviou ao DNPM os documentos 
necessários, porém a correta verificação da veracidade dessas informações só foi feita após o rompimento. Percebe-se que por um lado há uma empresa que pouco se importa com os danos irreparáveis que suas omissões podem causar, e, de outro, um órgão fiscalizador sem recursos para operar e extremamente falho. O resultado disso são danos irreparáveis no meio ambiente e na vida de centenas de pessoas.

\section{REFERÊNCIAS BIBLIOGRÁFICAS}

AGÊNCIA NACIONAL DE ÁGUAS. Fiscalização de barragens. Brasília: ANA. Disponível em: http://www3.ana.gov.br/portal/ANA/panorama-das-aguas/barragens/fiscalizacao-de-

barragens/fiscalizacao-de-barragens. Acesso em: 23 maio 2019.

AGÊNCIA NACIONAL DE MINERAÇÃO. Relatório do núcleo de regimento interno. Brasília, 2018. Disponível em: http://www.anm.gov.br/dnpm/documentos/anexo-i-regimento-interno/view. Acesso em: 23 maio 2019.

AGÊNCIA NACIONAL DE MINERAÇÃO. Segurança de barragens - Legislação federal brasileira em segurança de barragens comentada. Brasília, 2018. Disponível em: http://www.anm.gov.br/assuntos/barragens/e-book-livre-legislacao-federal-brasileira-em-segurancade-barragens-autor-luiz-paniago-neves. Acesso em: 23 maio 2019.

ANTUNES, Paulo de Bessa. Direito Ambiental. 12. Ed. Rio de Janeiro: editora Lumen Juris, 2019.

BRASIL. Departamento Nacional de Produção Mineral. Portaria nº 526, de 09 de dez. de 2013. Art. $6^{\circ}, \S 2^{\circ}$. Brasília, 09 de dezembro de 2013. Disponível em: http://www.anm.gov.br/acesso-ainformacao/legislacao/portarias-do-diretor-geral-do-dnpm/portarias-do-diretor-geral/portaria-no-526em-09-12-2013-do-diretor-geral-do-dnpm/view. Acesso em: 21 maio 2019.

. Diário oficial da União. Resolução ${ }^{\circ}$ 4, de 15 de fevereiro de 2019. Agência Nacional de Mineração/Ministério de Minas e Energia. Brasília, 15 de fevereiro de 2019. Disponível em: http://www.in.gov.br/materia/-/asset_publisher/Kujrw0TZC2Mb/content/id/63799094/do1-2019-0218-resolucao-n-4-de-15-de-fevereiro-de-2019-63799056. Acesso em: 13 ago. 2019.

Lei $\mathrm{n}^{\circ}$ 12.334, de 20 de set. de 2010. Estabelece a Política Nacional de Segurança de Barragens destinadas à acumulação de água para quaisquer usos, à disposição final ou temporária de rejeitos e à acumulação de resíduos industriais, cria o Sistema Nacional de Informações sobre Segurança de Barragens. Brasília, 20 de setembro de 2010. Disponível em: http://www.planalto.gov.br/ccivil_03/_Ato2007-2010/2010/Lei/L12334.htm. Acesso em: 12 ago. 2019.

Tribunal de Contas da União. TC 032.034/2015-6, 2016. Disponível em:

https://portal.tcu.gov.br/lumis/portal/file/fileDownload.jsp?fileId=8A8182A25753C20F0157587B1F 4C0870\&inline $=1$. Acesso em: 10 abr. 2019. 